\title{
Neural prediction model for microwave calcination-sulphuric acid leaching of germanium from zinc oxide dust
}

\author{
Wankun WANG ${ }^{1,2, a}$, Fuchun WANG ${ }^{1,2, b}$ and Fanghai LU $^{1,2, c}$ \\ ${ }^{1}$ Key Laboratory of Light Metal Materials Processing Technology of Guizhou Provinces, Guiyang \\ 550003, China; \\ ${ }^{2}$ chool of Materials and Metallurgical Engineering, Guizhou Institute of Technology, Guiyang 550003, \\ China \\ awangwankun@foxmail.coml, b Correspondence:fuchunhelichun@126.com, c791457506@qq.com
}

Keywords: zinc oxide dust; germanium; microwave calcinations; artificial neural network.

Abstract. Based on the study of artificial neural network, the neural model was established for the prediction of germanium extraction from zinc oxide dust by microwave calcination-sulphuric acid leaching. Microwave heating temperature, liquid-solid ratio, leaching time, initial concentration of sulphuric acid and leaching temperature were the significant factors for the process. The results indicated that the neural network prediction model was reliable, the forecast and actual values fitted well. The model could be used to predict the regeneration experiments with high credibility and practical significance. The accuracy of convergence of the model has reached $10^{-5}$.

\section{Introduction}

The neural network technology as a new technology of artificial intelligence is one of the frontier research direction of the rapid development of the international. The neural network is widely used in neurons are connected to each other into the complex network system, reflects a kind of human brain nervous system simplification, abstraction and simulation. With the development of research, neural networks have been widely used in telecommunications ${ }^{[1,2]}$, biomedical engineering ${ }^{[3,4]}$, chemical engineering ${ }^{[56,7]}$, automatic control[8,9,10], and expert systems ${ }^{[11,12,13]}$.

Neural network is a dynamic network system by a large number of neurons interconnected by highly nonlinear, adaptive, strong self-learning and self-organizing ability and massive parallelism and fault tolerance, so it has many traditional signal and information processing technology and not the advantage ${ }^{[14]}$.

In the present study, a neural model was established for the predicting the leaching ratios of Ge extraction from $\mathrm{ZnO}$ dust through microwave calcination-sulphuric acid leaching process.

\section{Establishment of neural network model}

The effects of microwave roasting- sulphuric acid leaching process on germanium (Ge) extraction from zinc oxide smoke $(\mathrm{ZnO})$ contain microwave heating temperature $\left(\mathrm{A},{ }^{\circ} \mathrm{C}\right)$, liquid-solid ratio $(\mathrm{B}$, $\mathrm{mL} / \mathrm{g})$, leaching time $(\mathrm{C}, \mathrm{h})$, initial concentration of sulphuric acid $(\mathrm{D}, \mathrm{mol} / \mathrm{L})$ and leaching temperature $\left(\mathrm{E},{ }^{\circ} \mathrm{C}\right)$. So the input of the prediction model for the micro distribution of microwave heating temperature (A), liquid-solid ratio (B), leaching time (C), initial concentration of sulphuric acid (D) and leaching temperature (E), the range of control input, each test under the condition of germanium leaching ration (Y, \%) as the output of the prediction model. Table 1 showed the input and output data. 
Table 1 Experimental results of microwave calcination-sulphuric acid leaching

\begin{tabular}{|c|c|c|c|c|c|c|}
\hline Run & $\begin{array}{c}\text { Microwave } \\
\text { heating } \\
\text { temperature } \\
\left(\mathrm{A},{ }^{\circ} \mathrm{C}\right)\end{array}$ & $\begin{array}{l}\text { liquid-solid } \\
\text { ratio (B, } \\
\mathrm{mL} / \mathrm{g})\end{array}$ & $\begin{array}{l}\text { Leaching } \\
\text { time }(\mathrm{C}, \mathrm{h})\end{array}$ & $\begin{array}{c}\text { Initial } \\
\text { concentration } \\
\text { of sulphuric } \\
\text { acid (D, } \\
\text { mol/L) }\end{array}$ & $\begin{array}{c}\text { Leaching } \\
\text { temperature } \\
\left(\mathrm{E},{ }^{\circ} \mathrm{C}\right)\end{array}$ & $\begin{array}{l}\text { Leaching } \\
\text { ratios } \\
(\mathrm{Y}, \%)\end{array}$ \\
\hline 1 & 310 & 8 & 4 & 12.6 & 80 & 50.86 \\
\hline 2 & 290 & 6 & 3 & 9.5 & 70 & 52.75 \\
\hline 3 & 290 & 6 & 3 & 9.5 & 70 & 56.5 \\
\hline 4 & 270 & 8 & 4 & 12.6 & 60 & 55.28 \\
\hline 5 & 310 & 4 & 2 & 12.6 & 80 & 56.16 \\
\hline 6 & 310 & 4 & 2 & 12.6 & 60 & 57.15 \\
\hline 7 & 290 & 6 & 3 & 9.5 & 70 & 56.08 \\
\hline 8 & 330 & 6 & 3 & 9.5 & 70 & 57.41 \\
\hline 9 & 310 & 8 & 4 & 6.3 & 80 & 72.61 \\
\hline 10 & 310 & 4 & 4 & 6.3 & 80 & 68.89 \\
\hline 11 & 270 & 4 & 2 & 6.3 & 60 & 70.22 \\
\hline 12 & 310 & 8 & 2 & 6.3 & 60 & 70.87 \\
\hline 13 & 310 & 8 & 2 & 12.6 & 60 & 74.66 \\
\hline 14 & 270 & 4 & 4 & 6.3 & 80 & 70.81 \\
\hline 15 & 310 & 8 & 2 & 6.3 & 80 & 75.24 \\
\hline 16 & 270 & 8 & 2 & 12.6 & 60 & 71.82 \\
\hline 17 & 270 & 8 & 2 & 12.6 & 80 & 52.41 \\
\hline 18 & 290 & 6 & 3 & 9.5 & 70 & 53.84 \\
\hline 19 & 250 & 6 & 3 & 9.5 & 70 & 51.22 \\
\hline 20 & 270 & 4 & 4 & 12.6 & 80 & 52.00 \\
\hline 21 & 310 & 4 & 2 & 6.3 & 60 & 50.68 \\
\hline 22 & 270 & 4 & 2 & 12.6 & 60 & 51.02 \\
\hline 23 & 290 & 10 & 3 & 9.5 & 70 & 50.23 \\
\hline 24 & 310 & 8 & 4 & 12.6 & 60 & 52.33 \\
\hline 25 & 290 & 6 & 3 & 9.5 & 70 & 62.62 \\
\hline 26 & 290 & 6 & 3 & 9.5 & 90 & 63.13 \\
\hline 27 & 290 & 6 & 5 & 9.5 & 70 & 65.66 \\
\hline 28 & 270 & 4 & 4 & 6.3 & 60 & 67.86 \\
\hline 29 & 270 & 8 & 2 & 6.3 & 80 & 65.68 \\
\hline 30 & 290 & 6 & 3 & 15.8 & 70 & 69.67 \\
\hline 31 & 270 & 4 & 2 & 12.6 & 80 & 74.64 \\
\hline 32 & 310 & 8 & 2 & 12.6 & 80 & 70.28 \\
\hline 33 & 310 & 4 & 4 & 6.3 & 60 & 60.12 \\
\hline 34 & 270 & 8 & 2 & 6.3 & 60 & 56.24 \\
\hline 35 & 270 & 4 & 4 & 12.6 & 60 & 33.11 \\
\hline 36 & 290 & 2 & 3 & 9.5 & 70 & 75.35 \\
\hline 37 & 310 & 8 & 4 & 6.3 & 60 & 68.32 \\
\hline 38 & 290 & 6 & 3 & 9.5 & 70 & 78.2 \\
\hline 39 & 270 & 4 & 2 & 6.3 & 80 & 38.64 \\
\hline
\end{tabular}

\section{Results and discussion}

The data in Table 1 were taken as the training samples of the neural network prediction model. In network training process, network weights and threshold of the network were obtained through 10 iterations. The training convergence curve of the neural network prediction model was shown in Figure 1. From the figure 1, it found that the convergence precision was 0.00001 , which achieved the goal. 


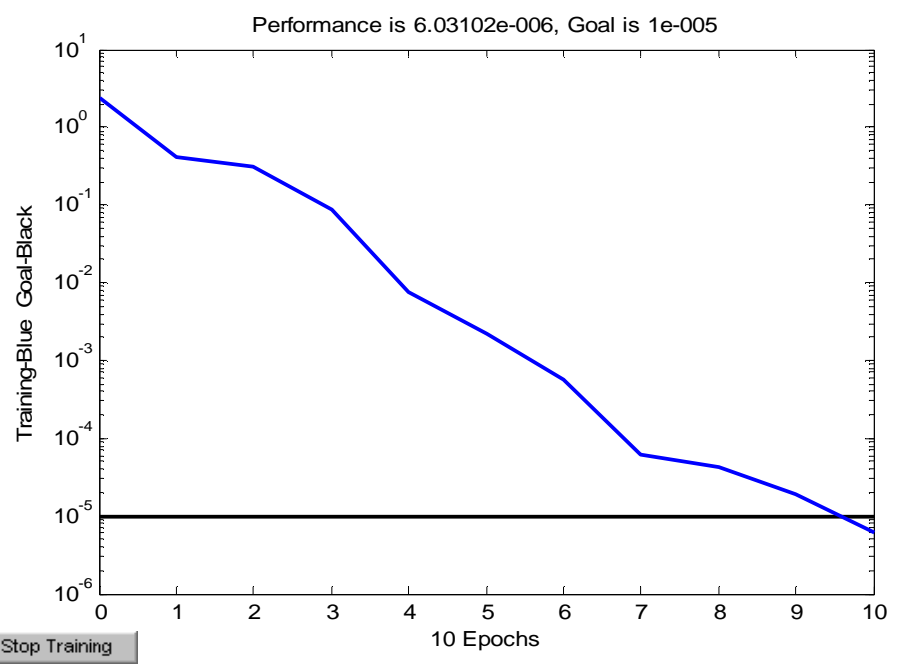

Fig.1 Iterative convergence curve of the anti-predicted model

Figure 2 showed the leaching rate of germanium value curve and the actual 3D graph for microwave heating temperature $\left(270 \sim 350^{\circ} \mathrm{C}\right)$, liquid-solid ratio $(4 \sim 10 \mathrm{~mL} / \mathrm{g})$, leaching time $(1 \sim 5 \mathrm{~h})$, initial concentration of sulphuric acid $(6 \sim 12 \mathrm{~mol} / \mathrm{L})$ and leaching temperature $\left(60 \sim 80^{\circ} \mathrm{C}\right)$.
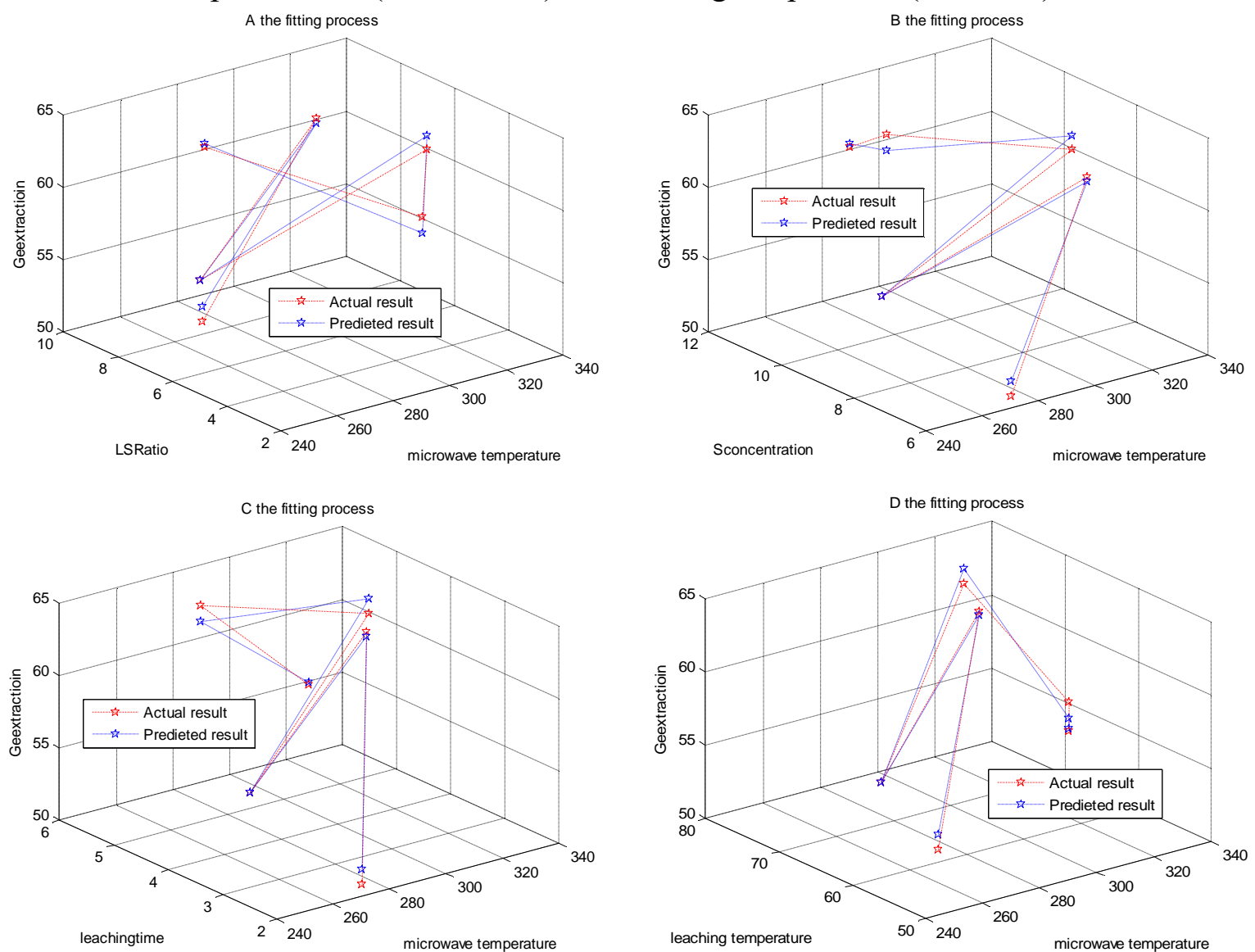

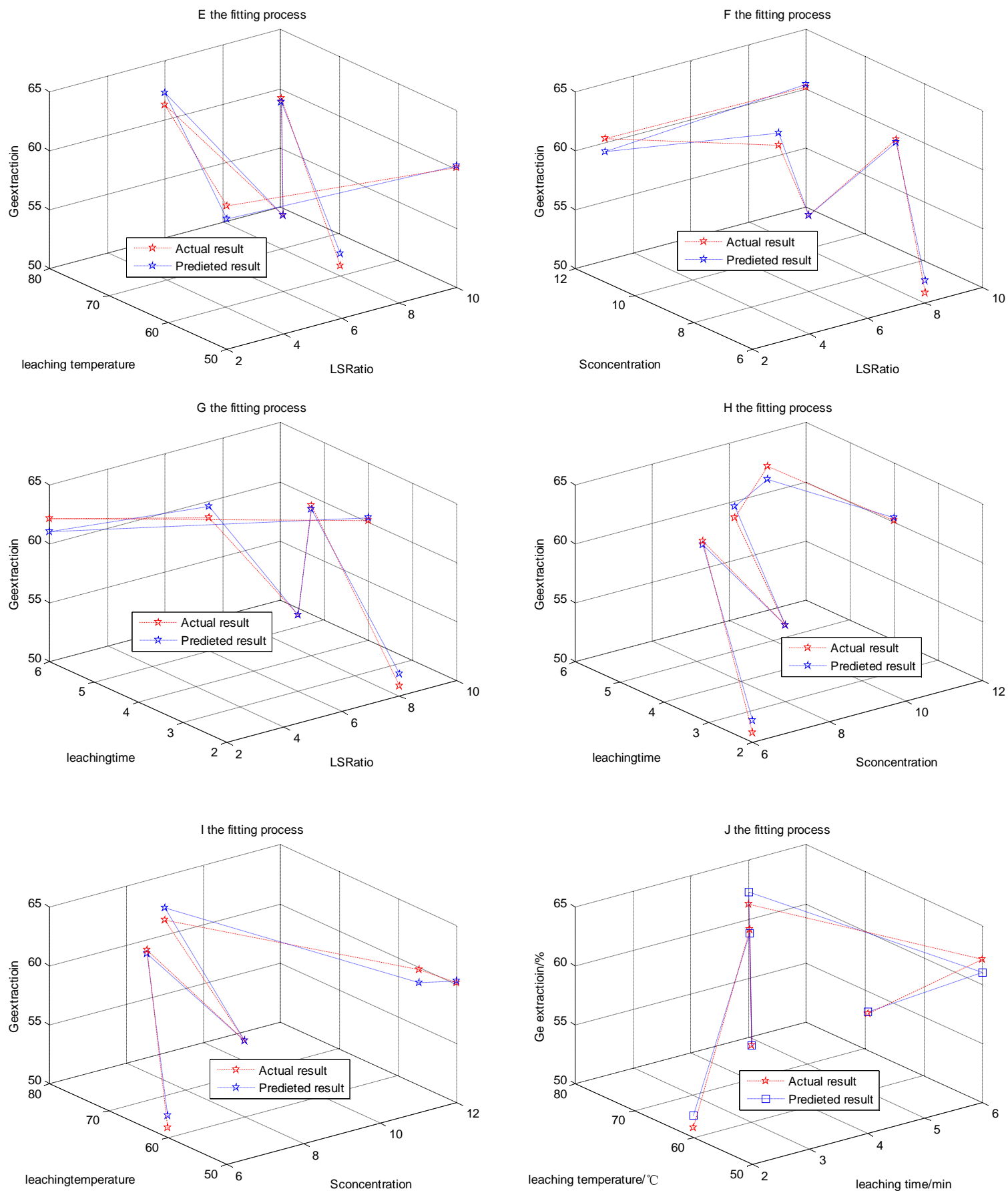

Fig.2 Comparisons between actual and predicted results of Ge extraction

As seen from the Figure 2, the prediction results of the prediction model are basically consistent with the actual values. In summary, microwave heating temperature, liquid-solid ratio and initial concentration of sulphuric had great effects on the leaching rate of germanium. It could be concluded that the model had a good adaptability and accuracy. Therefore, it was feasible to use this neural network model to predict the leaching percentages of $\mathrm{Ge}$ from $\mathrm{ZnO}$ dust by microwave calcination-sulphuric acid leaching.

\section{Conclusions}

The neural network model was established for predicting the leaching percentages of Ge from $\mathrm{ZnO}$ dust through microwave calcination-sulphuric acid leaching process. Through the network training and verification for this model, it showed that the predicted values coincided well with the 
experimental values. And the convergence accuracy for this model reached 0.00001 . Therefore this model could be used to predict the production conditions required for different production purposes in the process of Ge recovery, which could help to reduce the groping process and the production cost.

\section{Acknowledgements}

This work was supported by the National Natural Science Foundation of China (51404081, 51504073, 51664010), the Research Program of the Education Department of Guizhou Province (KY [2015]433), and the Research Program of Talented Scholars of Guizhou Institute of Technology (XJG20141104)

\section{References}

[1] Ramazan Coban, "A context layered locally recurrent neural network for dynamic system identification," Engineering Applications of Artificial Intelligence, 60(9) (2013),35-54.

[2] M. Gholami, N. Cai, R.W. Brennan, "An artificial neural network approach to the problem of wireless sensors network localization," Robotics and Computer-Integrated Manufacturing, 29(1) (2013), 96-109.

[3] Hilleke Hulshoff Pol, Edward Bullmorec, "Neural networks in psychiatry," European Neuropsychopharmacology,23(1) (2013), 1-6.

[4] Bi-Qin Lai, Jun-Mei Wang, Jing-Jing Duan,etal., " The integration of NSC-derived and host neural networks after rat spinal cord transection,” Biomaterials,,34(12) (2013), 2888-2901.

[5] José P.S. Aniceto, Daniel L.A. Fernandes,etal. , "Modeling ion exchange equilibrium of ternary systems using neural networks," Desalination, 309(15) (2013), 267-274.

[6] Katarina M. Rajković, Jelena M. Avramović, Petar S. Milić,etal, "Optimization of ultrasound-assisted base-catalyzed methanolysis of sunflower oil using response surface and artifical neural network methodologies," Chemical Engineering Journal, 215-216 (15) (2013), 82-89.

[7] Rasoul Irani, Reza Nasimi, "Application of artificial bee colony-based neural network in bottom hole pressure prediction in underbalanced drilling," Journal of Petroleum Science and Engineering, 78(1) (2011), 6-12.

[8] P. Gil, J. Henriques, A. Cardoso, A. Dourado, "On affine state-space neural networks for system identification, Global stability conditions and complexity management," Control Engineering Practice, 21(4)(2013), 518-529.

[9] Patrick Opdenbosch, Nader Sadegh, Wayne Book, "Intelligent controls for electro-hydraulic poppet valves," Control Engineering Practice,21(6) (2013), 789-796.

[10] Hong-Gui Han, Jun-Fei Qiao, Qi-Li Chen, "Model predictive control of dissolved oxygen concentration based on a self-organizing RBF neural network," Control Engineering Practice, 20(4) (2012), 465-476.

[11] H.S. Wang, Y.N. Wang, Y.C. Wang, "Cost estimation of plastic injection molding parts through integration of PSO and BP neural network," Expert Systems with Applications,40(2) (2013), 418-428. [12] Ivan Maric, "Optimization of self-organizing polynomial neural networks," Expert Systems with Applications, 31(2013), 4528-4538.

[13] D. Peteiro-Barral, V. Bolón-Canedo, A. Alonso-Betanzos, et al., "Toward the scalability of neural networks through feature selection," Expert Systems with Applications, 40(8) (2013), 2807-2816.

[14]Dongna Lu, "Nonlinear model predictive control based on Neural Network,"(master's thesis, Central South University of China, 2009) 